phage deoxyribonucleic acid and phage protein, in a $T$ phage-E. coli complex. The nucleotide composition, estimated from the incorporation of phosphorus-32 into individual nucleotides of ribonucleic acid, was unlike that of normal $E$. coli and was specific to the phage species $\left(T_{2}\right.$ and $T_{3}$ were compared). It was not affected by various conditions which prevented phage deoxyribonucleic acid synthesis or the production of progeny phage. But it corresponded fairly well to the nucleotide composition of phage deoxyribonucleic acids, the replacement of the ribonucleic acid pyrimidines for the phage deoxyribonucleic acid pyrimidines being taken into acsount. Thus, the ribonucleic acid synthesis at an early period of phage infection seems to be under direct control of phage deoxyribonucleic acid. $Y$. Hotta (Biological Institute, Nagoya University) gave a convincing proof that in the early development of fern gametophytes one-dimensional cell division (leading to the elongation of the plant) and two-dimensional division which followed (leading to the fan-like growth) depended on the amount of protein synthesis. One of the simplest forms of differentiation was thus correlated with the biochemical activity of the cell. 8-Azaguanine, which, like amino-acid analogues, specifically inhibited the two-dimensional cell division, besides being incorporated into ribonucleic acid, produced an appreciable amount of an unknown ultraviolet-absorbing material (probably a nucleotide) in an alkaline digest of ribonucleic acid.

As regards the biosynthesis of deoxyribonucleic acid, T. and R. Okazaki (Biological Institute, Nagoya University) showed that the majority of the acid. soluble deoxyribosidic compounds, found in a deoxyriboside-requiring strain of Lactobacillus acidophilus cells, were more than simple nucleosides. The main component was probably a derivative of thymidine diphosphate, and its behaviour under various conditions suggested that it might be an intermediate in deoxyribonucleic acid synthesis. It was also shown that the deoxyribonucleic acid synthesis in the same bacteria can proceed in the absence of ribonucleic acid and protein syntheses and vice versa, while ribonucleic acid synthesis and protein synthesis were inhibited together either by uracil deficiency or by amino-acid deficiency. The inter-as well as intra-molecular homogeneity of deoxyribonucleic acid, with respect to labelling with phosphorus-32, was evidenced by the experiments of Sakaki (Chemical Laboratory of General Education, Nagoya University), using rabbit appendix removed $30 \mathrm{~min}$. after injection with phosphorus-32. The role of pre-existing deoxyribonucleic acid in the incorporation of phosphorus-32 into isolated nuclei of rabbit appendix was discussed by M. Sekiguchi and A. Sibatani (Cytochemistry Laboratory, Yamaguti Medical School). Incorporation into nucleic acid was abolished by treating these nuclei with deoxyribonuclease I but could be restored by adding deoxyribonucleic acid or ribonucleic acid of heterologous origin; even the addition of chondroitin sulphate was effective in restoring the lost activity, suggesting that the effect of added substances was physico-chemical, rather than due to the specificity or the supply of energy-rich nucleotides. The role of deoxyribonucleic acid synthesis in enzyme formation was discussed by N. Otsuji and Y. Takagi (Department of Biology, Faculty of Science, and Department of Biochemistry, Medical School, Osaka University). Intact and 'shocked' protoplasts of $E$. coli strains were capable of forming tryptophanase (by induction) and deoxyribonucleic acid. The presence of 5-bromouracil and 6-azauracil effectively inhibited enzyme formation by preparations of strain $K-12$, while they had no effect when tested with intact cells. With preparations of the thymine-requiring strain $15 T^{-}$, enzyme formation and deoxyribonucleic acid synthesis depended on the presence of thymine. In the absence of thymine only a small amount of enzyme was formed at an early stage.

A limited number of the proceedings of this symposium (in English) can be obtained on request, free of eharge, from the Association for Nucleic Acid Research, c/o Prof. T. Suzuki, Department of Pharmacology, University of Kyoto Medical School, Yosida, Kyoto, Japan.
A. Sibatani

\title{
SALT MARSHES
}

A SMALL, representative, and successful conference on salt marshes was held at Sapelo Island, Georgia, the Marine Institute of that University, during March 24-29. It was sponsored by the National Science Foundation and the University of Georgia.

There were forty-seven members, including two from Germany, one from Holland, one from New Zealand, and one from Great Britain. All the others were from the United States and Canada. Dr. R. A. Ragotzkie and his colleagues organized both conference and excursions, and all participants are most grateful to them.

The Conference was under the presidency of Dr. A. C. Redfield of Woods Hole, and on each separate day a discussion leader was in charge of the morning session. The first day was devoted to papers on salt marshes as land forms. J. A. Steers acted as chairman and introduced the subject by a paper on the physiography of salt marshes, on both temperate and tropical coasts. L. M. van Straaten followed with an account of the origin of the tidal flats of Holland.
R. A. Ragotzkie examined marsh drainage patterns, and were followed by R. J. Russell and J. P. Morgan who described the morphology of the Louisiana marshes and the coastal changes following hurricane 'Audrey'. In the afternoon there was a field trip to the beach on Sapelo Island, and a few members made a long excursion on the mainland to see the terrace formations characteristic of the coast. In the evening J. Zeigler showed some very pertinent films, taken from the air, of large parts of the Carolina and Georgia coast.

The second day was devoted to a discussion on the vegetation of salt marshes. V. J. Chapman provided a general perspective of the vegetation and showed that maritime salt marshes can be divided into a number of different groups in the different parts of the world. The relationships within a group and between groups can be determined either by analysis of the various floral elements or else by means of affinity coefficients. After E. T. Moul had described the algal flora of salt pans on a marsh the remainder of the morning was devoted to a paper by $P$. $R$. 
Burkholder on some microbiological aspects of marine productivity in shallow waters. He pointed out that for the annual Spartina grass crop only 10 per cent of the dead material remained after being in water for 360 days. This means that mibrobiological decomposition is very active and that on such marshes relatively little organic matter accumulates.

The afternoon was devoted to field trips in groups around Sapelo Island. In the evening W. Hantzchel gave an account of the palæontological significance of molluscan trails and burrows on tidal flats of the North Sea.

On the third day the salt marsh as an eco-system was debated. The discussion was introduced by A. C. Redfield, who gave an account of the movement of heat, salt and water in the soil of Barnstaple Marsh, Mass. Analysis of the salt movements indicated that underlying fresh water was diffusing up and counteracting the downward movement of salt water, though this movement was not sufficient to affect the thermal waves. The next three papers were all concerned with productivity. L. R. Pomeroy gave an account of the diatom flora on Sapelo Island Marshes, A. E. Smalley showed that creekside Spartina grass on the Georgia marshes continued to grow after July whereas on the high marsh this was not the case, and $J$. M. Teal summarized the metabolism of the eco-system in the light of the information available. Although a number of gaps remain to be filled before a final, more accurate, calculation is possible, it seems that about 46 per cent of the energy utilized by the Spartina and algæ is transformed and 54 per cent is lost.
The afternoon was devoted to a trip to Blackbeard Island to study the dune ridge system. In the evening A. C. Redfield gave an account of his work on Barnstaple Marsh, Massachussetts.

On the fourth day the use of salt marshes for historical records was discussed. H. M. Raup and F. Johnson gave an account of the archæology and salt marshes of Grassy Island in Massachussetts. E. S. Barghorn demonstrated how the Boylston Street peat at Boston and the peat of the Barnstaple Marsh could be used both archæologically and by radiocarbon dating to measure rate of marsh develop. ment in relation to land subsidence. The data indicate a mean subsidence-rate of about 6 in. per century for the past 5,500 years. J. R. Vallentyne discussed some aspects of the biochemistry of mud, particularly in respect of the breakdown of the chlorophyll pigments. The final contribution was by W. Schafer on elements of actuo-palæontology in relation to beaches and shallow seas.

The afternoon was given over to various field trips and one group was flown over the marshes and mainland terraces in the plane belonging to the Woods Hole Oceanographic Institute. This also gave participants an appreciation of just how useful such a plane can be for coastal and oceanographic work. The meeting terminated with a dinner given by $\mathbf{M r}$. and Mrs. R.J. Reynolds, the owners of Sapelo Island. The University of Georgia is to be congratulated on initiating such a useful conference, which will undoubtedly bear results for a number of years to come.

V. J. Chapman

J. A. StrerRs

\section{THE CARNEGIE INSTITUTION OF WASHINGTON}

\section{REPORT FOR 1956-57}

T HE Yearbook of the Carnegie Institution of Weshington, covering the year July 1, 1956June $30,1957^{*}$, contains the report of the president and those of Departments and special studies as well as of the Executive Committee and of the suditors. The study of celestial objects as radio sources continued, both at the Mount Wilson and Palomar Observatories, and in the Department of Terrestrial Magnetism, where a programme of flux messurements on a few of the intense radio sources over a wide band of the useful spectrum has become an important project in radio-astronomy. Preliminary scans of the Sun's face made by an antenna array, specially designed for detailed examination of solar radio emission, have revealed localized light sources which move across the disk as the Sun rotates. Further investigation of radio noise from Jupiter indicates that there may be a single centre of activity on the planet with an approximately uniform rotational period, and the construction of a radio-telescope to be equipped with a $60 \mathrm{ft}$. dish has commenced.

At Mount Wilson spectroscopic observations were carried out with all major telescopes except the 48-in. Schmidt. The photoelectric scanning spectrograph was applied to the study of the energy distribution of the high-velocity giant Arcturus and of two

* Carnegie Institution of Washington. Year Book, 56, July 1 , 1956-June 30, 1957. Pp. xi +425+xllil. (Washington, D.C. : Carnegie paper bound. red giants in M92. A project on stellar composition and related nuolear processes at Mount Wilson and Palomar Observatories, sponsored by the Physics Division of the United States Air Force Office of Scientific Research, attempts to obtain new astronomical results relevant to theories of the origin of the elements, and to bring together a group of nuclear physicists and astrophysicists interested in aspects of this fundamental question. Photovisual observations of the Cepheids in the outer field of the Andromeds nebula, 96 ' south preceding the nucleus, were concluded and also the investigation of the variables in the Draco system. The main effort of the Committee on Image Tubes for Telescopes was directed towards the development of thin-film image converters.

Seismic and gravity studies continue to form an important part of the Department of Terrestrial Magnetism's work, and in co-operation with the United States National Committee for the International Geophysical Year the Department has undertaken a seismic study in the Andean highlands, using as indicators the explosions normally set off in the operation of large open-pit copper mines in southern Peru and northern Chile. Jointly with the Geophysical Laboratory, an investigation was commenced of regional regularities in the ages of the Precambrian rock exposures, which has already indicated that over much of Arizona, New Mexico, Colorado and Wyoming rocks were formed 1,300-1,400 million years ago and some in Ontario 2,600 million years ago. Concordant rubidium- 